\title{
$\gamma$-Butyrolactone: An Anesthetic with Hyperthermic Action in the Rat
}

$\gamma$-butyrolactone (GBL) is an anesthetic agent with some interesting properties: It causes a selective increase of brain dopamine presumably by antagonizing transmitter release from nerve terminals, as has been shown with biochemical ${ }^{1,2}$ and fluorescence microscopic methods $^{3}$. Moreover, GBL has been reported to be an endogenous brain metabolite derived from glutamate through $\gamma$-aminobutyrate ${ }^{4}$. We now report a hyperthermic action of GBLin the rat which is a unique feature for an anesthetic compound.

Experiments were performed in unrestrained, male albino rats held in individual cages at an ambient temperature of $30^{\circ} \mathrm{C}$. Body temperature was continuously monitored with an intraperitoneal temperature transmitter $^{5,6}$ which had been implanted approximately 1 week before the experiments. Motor activity was measured with a force recorder ${ }^{5}$ placed under the animal's cage. GBL was administered by intraperitoneal injection at doses of 200,400 , and $700-800 \mathrm{mg} / \mathrm{kg}$, using a counterbalanced design with intervals of at least 2 days between experiments.

A dose of $200 \mathrm{mg} / \mathrm{kg}$ GBL abolished spontaneous motor activity for $87 \mathrm{~min}$ and decreased body temperature by $0.7^{\circ} \mathrm{C}$ (士 $0.09 \mathrm{SEM}$ ) (Figure). A dose of $400 \mathrm{mg} / \mathrm{kg}$ abolished motor activity for approximately $3 \mathrm{~h}$. Immediately after administration of the drug body temperature decreased by $0.5^{\circ} \mathrm{C}$ ( \pm 0.13 SEM). Approximately 20 min after injection, body temperature started to rise, and reached a peak of $1.3^{\circ} \mathrm{C}( \pm 0.16 \mathrm{SEM})$ above the control level after 70-90 min. Subsequently, body temperature decreased to $1^{\circ} \mathrm{C}( \pm 0.11$ SEM) below the initial level, at a time when the animal started to resume spontaneous motor activity. Doses of $700-800 \mathrm{mg} / \mathrm{kg}$ GBL which depressed motor activity for $5-8 \mathrm{~h}$, had a similar triphasic action on body temperature with a peak

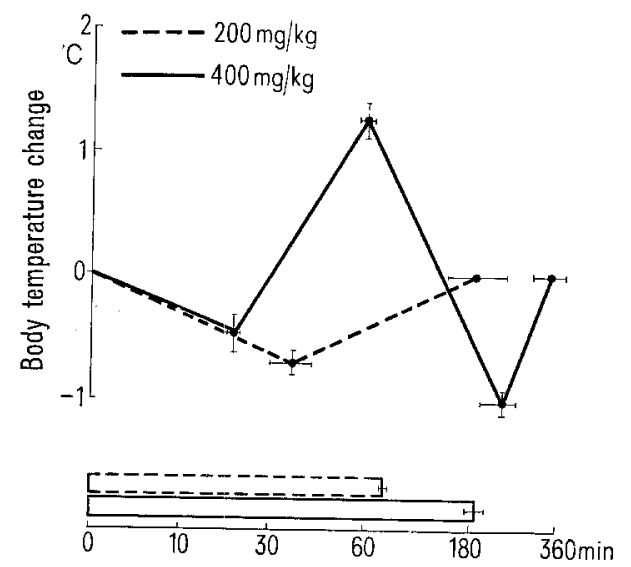

Effect of $\gamma$-butyrolactone $(-\cdots-200 \mathrm{mg} / \mathrm{kg}$ and $-400 \mathrm{mg} / \mathrm{kg})$ on body temperature. The means and standard errors of the minimum and maximum values, and the time of return to the baseline level are shown for 5 subjects. The horizontal bars represent the duration of abolished motor activity for the 2 doses.

\section{Transfer of Metallic Mercury into the Foetus}

Metallic mercury is known to cross the blood brain barrier much more readily than ionic mercury 1, 2 . No similar studies have been reported on the relative transport rates of these forms of mercury from mother to foetus. of $1.5^{\circ} \mathrm{C}( \pm 0.37 \mathrm{SEM})$ above the control level. However, with such high doses a prolonged depression of motor activity, feeding and drinking was apparent in some animals, indicating a possible toxic effect. To test the possibility that the changes of body temperature are due to an increase of cerebral dopamine, synthesis of catecholamines was inhibited with $\alpha$-methyl-p-tyrosine methyl ester (AMPT; $250 \mathrm{mg} / \mathrm{kg}$ i.p. 40-70 min prior to GBL). It had been shown previously ${ }^{1}$ that the increase of brain dopamine by $\gamma$-hydroxy butyrate (GHB; a metabolite of GBL) could be prevented by pretreatment with AMPT. In our experiments pretreatment with AMPT did not significantly influence the effect of GBL $(400 \mathrm{mg} / \mathrm{kg})$ on body temperature (peak increase $1.0^{\circ} \mathrm{C} \pm 0.22 \mathrm{SEM}$ ) and motor activity. Therefore, it seems unlikely that these effects are due to an increase of brain dopamine. The high level of endogenous GHB in the hippocampus and mesodiencephalon of the guinea-pig ${ }^{2}$ raise the possibility that exogenous GBL might exert some of its effects by acting on non-dopaminergic cerebral structures. Recent experiments in chronic thalamic rats ${ }^{7}$ indicate that the presence of telencephalic structures is necessary for GBL hyperthermia, as the rise of body temperature was practically abolished in this preparation, whereas hypothermia and anesthesia were still present. It remains unknown, however, by what mechanisms GBL induces hyperthermia during anesthesia.

Zusammenfassung. $\gamma$-butyrolacton (400 $\mathrm{mg} / \mathrm{kg}$ i.p.) bewirkt bei der Ratte eine triphasische Änderung der Körpertemperatur mit einer hyperthermen Komponente. Diese für ein Narkosemittel ungewöhnliche Hyperthermie kann nicht durch eine Erhöhung der Dopaminkonzentration im Gehirn erklärt werden, da sie nach Hemmung der Katecholaminsynthese immer noch vorhanden ist.

\section{A. A. Borbély and J. P. Huston 8}

Institute of Pharmacology, University of Zürich, Gloriastrasse 32, CH-8006 Zürich (Switzerland), 14 June 1972.

1 G. L. Gessa, F. Crabai, L. Vargid and P. F. Spano, J. Neurochem. 15,377 (1968).

2 R. H. Roth, Biochem. Pharmac. 19, 3013 (1970).

3 G. K. Aghajanian and R. H. Roth, J. Pharmac. exp. Ther. 175, $131(1970)$.

4 R. H. Roth and N. J. Giarman, Biochem. Pharmac. 19, 1087 (1970).

5 A. A. Borbíly, in Proc. 4th Int. Congr. of Pharmacology, Basel 1969 (Schwabe, Basel/Stuttgart 1970), vol. V, p. 295.

6 H. Graf and A. Borbély, Experientia 22, 339 (1966).

7 A. A. Borbély, J. P. Huston and I. R. BAUMANN, in The Pharmacology of Thermoregulation (Eds. P. Lomax and E. Schönbaum; Karger, Basel), in press.

8 This study has been supported by the Swiss National Science Foundation, grants No. 3.287.69 and No. 3.693.71, and by the HartmanMueller Foundation for Medical Research. $\alpha$-methyl- $p$-tyrosine methyl ester was generously supplied by Hoffmann-La Roche, Basel.

In the present study Wistar rats $200-300 \mathrm{~g}$ were exposed to mercury vapour labelled with the ${ }^{203} \mathrm{Hg}$ isotope to give a specific activity of $15 \mu \mathrm{Ci} / \mu \mathrm{g}$ of mercury. The animals placed in metabolic cages were allowed to inhale 